\title{
Práticas Integrativas na Oncologia
}

CASSILETH, B.R.

The Complete Guide to Complementary Therapies in Cancer Care.

$1^{\text {a }}$ ed. Singapore: World Scientific Publishing, 2011. 354p.

I 1 Pamela Siegel, ${ }^{2}$ Nelson Filice de Barros I

1 Departamento de Saúde Coletiva, FCM-UNICAMP, Campinas-SP, Brasil. Endereço eletrônico: pamsky@mpc.com.br

2 Doutor em Saúde Coletiva; professor e pesquisador no Departamento de Saúde Coletiva, Faculdade de Ciências Médicas

(FCM-UNICAMP), Campinas-SP, Brasil. Endereço eletrônico: nelfel@uol.com.br

Recebida em: 03/05/2013

Aprovada em: 21/10/2013

DOI: http://dx.doi.org/10.1590/S0103-73312014000400018

Nas últimas duas décadas, tem havido grande propagação das práticas integrativas e complementares (PIC) nos Estado Unidos (EISENBERG et al., 1998). Com o intuito de apresentar informação essencial sobre essas práticas aos pacientes, sobreviventes e profissionais de saúde do câncer, Cassileth, médica do Memorial Sloan-Kettering Cancer Center, publicou o livro The Complete Guide to Complementary Therapies in Cancer Care (CASSILETH, 2011), organizado em sete partes, com 55 capítulos e 354 páginas.

A autora analisou 55 terapias classificadas em práticas baseadas na biologia, técnicas mente-corpo, práticas de manipulação corporal, terapias energéticas e sistemas médicos tradicionais. Cada uma das práticas é apresentada a partir do seguinte padrão: a definição; o que os profissionais dizem que a terapia faz; crenças sobre as quais as terapias se baseiam; pesquisa sobre as evidências até o momento; o que essa prática pode fazer por você e onde consegui-la. Evidentemente, este último item diz respeito a endereços físicos e eletrônicos nos EUA.

$\mathrm{Na}$ parte I, a autora inclui a acupuntura, medicina ayurvédica, medicina tradicional chinesa, homeopatia, cura americana nativa e a medicina naturopática. $\mathrm{Na}$ parte II, ela analisa as seguintes terapêuticas: suplementos dietéticos, jejum 
e sucos, florais, ervas medicinais, macrobiótica e vegetarianismo. As terapias mente-corpo são apresentadas na parte III: biofeedback, hipnose e auto-hipnose, visualização, meditação, o efeito placebo, qigong, taichi e yoga. A seguir, ela ilustra algumas técnicas para ganhar força: acupressão, Alexander e Pilates, hidroterapia, massoterapia, exercícios físicos, reflexologia e rolfing. $\mathrm{Na}$ parte $\mathrm{V}$, trata de técnicas que estimulam o bem-estar através dos sentidos: aromaterapia, arteterapia, dança como terapia, terapia do humor e do som. Tratamentos alternativos sem comprovação, segundo a autora, são citados na parte VI: apiterapia, antineoplastons, terapia celular, quelação, desintoxicação do cólon, terapia craneossacral, terapia enzimática, metabólica, neural, à base de oxigênio e cartilagem de tubarão e bovina. Terapias por ela chamadas de alternativas e de energia externa estão reunidas na parte VII de seu livro, a saber: quiropraxia, cristais, terapia eletromagnética, cura pela fé, fotografia Kirlian, oração e espiritualidade, xamanismo e toque terapêutico. A autora enfatiza, ainda, que nenhuma dessas terapias tem poder de cura sobre o câncer e que as remissões espontâneas ainda não são bem compreendidas ou estudadas.

Selecionamos o item "o que essa prática pode fazer por você", relativo à primeira terapia de cada uma das sete partes do livro, com o intuito de apresentar uma pequena amostra do material nesta resenha. Segundo a autora, "a acupuntura não seria uma alternativa realista para o diagnóstico moderno", mas sua simplicidade, atoxicidade, baixo custo e eficácia tornam essa técnica uma boa opção para vários tipos de dores crônicas e pode ser útil para combater os seguintes agravos: estresse, ansiedade, artrite e dores de cabeça.

Com relação aos suplementos dietéticos, a autora afirma que o ácido fólico em pequenas quantidades pode suplementar a dieta das mulheres grávidas, para reduzir a incidência de gravidezes problemáticas e de doenças cardíacas. A seguir, traz uma série de advertências, a saber: que um comprimido diário de vitaminas é desnecessário se o indivíduo ingere uma dieta saudável e balanceada, mas poderá ser útil nas dietas deficientes para suplementar nutrientes como o cálcio ou a vitamina $\mathrm{D}$ na prevenção contra a osteoporose. Megadoses de certos nutrientes lipossolúveis, tais como o betacaroteno, podem ser tóxicos e não substituem os nutrientes encontrados na dieta. Um alerta vermelho é levantado contra produtos que clamam estimular a energia, como os derivados da apicultura ou o chromium picolinate, para perder peso e aumentar 
a massa muscular, e toda uma oferta de cápsulas e produtos que apresentam

falsas alegações sobre o aumento da força e do bem-estar, e que apesar de não funcionarem, movimentam um mercado milionário.

O biofeedback é um procedimento não invasivo, que não acarreta riscos e cujo objetivo é produzir relaxamento. Muito embora um paciente possa se sentir relaxado, o dispositivo pode acusar o contrário, já que registra as funçôes do sistema nervoso autônomo, podendo ser, segundo a autora, mais útil para alguns do que o yoga, o zen budismo ou a meditação. A acupressão também é um procedimento não invasivo, pode ser autoadministrado e alivia dores e outros problemas para muitas pessoas. Segundo a autora, não deveria ser utilizado como o único tratamento em problemas ou doenças graves. A única contraindicação é que não deve ser aplicada próxima à área abdominal em mulheres grávidas e em varizes, feridas, machucados ou ossos fraturados.

Usada estritamente como uma técnica complementar, a aromaterapia é uma terapia agradável quando aplicada juntamente com banhos e massagens. Pode ajudar a relaxar, reduzir o estresse, aumentar o nível de prazer e a qualidade de vida, apesar de não existir evidência de que possa ajudar a prevenir ou curar doenças. Um dos cuidados é evitar a exposição prolongada devido à possibilidade de causar alergias.

Segunda a autora, não há evidência científica até o momento de que a apiterapia possa aumentar o nível de energia e aliviar os sintomas da artrite, gota, dor nas juntas e esclerose múltipla. Os relatos favoráveis existentes são narrativas subjetivas, e não experimentos controlados. Há, inclusive, registros científicos de ataques de asma após o uso da geleia real. E embora recomende não usar um quiroprático como um médico de família, a correta manipulação da coluna pode corrigir um deslocamento, minar a dor lombar, bem como melhorar a postura, aliviar cefaleias, tensão e desconfortos em geral.

Enfim, o livro serve como uma salvaguarda para os profissionais de saúde e usuários que desejam obter informações claras sobre o uso das PIC no câncer, haja vista a grande quantidade de informação com base pouco qualificada que atualmente circula pela internet. $\mathrm{O}$ livro traz uma visão geral das terapêuticas, temperado com um olhar crítico e um texto objetivo e de fácil compreensão, ao contrário de uma gama de livros promocionais disponíveis sobre as PIC com um valor relativo. 
Consideramos o livro como importante referência para os profissionais de saúde e gestores do SUS, principalmente para aqueles envolvidos com aplicações de algumas técnicas terapêuticas preconizadas pela Política Nacional de Práticas Integrativas e Complementares (BRASIL, 2006). ${ }^{1}$

\section{Referências}

BRASIL. Ministério da Saúde. Politica Nacional de Práticas Integrativas e Complementares. Ministério da Saúde: Brasília, 2006. 92p. Disponível em: http://portal.saude.gov.br/portal/ arquivos/pdf/pnpic_publicacao.pdf. Acesso em: 7 nov 2012.

CASSILETH, B.R. The Complete Guide to Complementary Therapies in Cancer Care. $1^{\text {a }}$ ed. Singapore: World Scientific Publishing, 2011. 354p.

EISENBERG, D.M. et al. Trends in Alternative Medicine Use in the United States, 19901997: Results of a Follow-up National Survey. JAMA, v. 280, p. 1569-1575, 1998.

\section{Nota}

${ }^{1}$ P. Siegel e N.F. de Barros participaram da concepção, redação do resenha e aprovação da versão final a ser publicada. 